\title{
Curriculum revisions for meeting the new ABET program-specific criteria in optical engineering
}

Paul Leisher, Sergio Granieri, Robert Bunch, Azad Siahmakoun, Charles Joenathan

Paul O. Leisher, Sergio C. Granieri, Robert M. Bunch, Azad Siahmakoun, Charles Joenathan, "Curriculum revisions for meeting the new ABET programspecific criteria in optical engineering," Proc. SPIE 9793, Education and Training in Optics and Photonics: ETOP 2015, 979321 (8 October 2015); doi: 10.1117/12.2223192

Event: Education and Training in Optics and Photonics: ETOP 2015, 2015, Bordeaux, France 


\title{
Curriculum revisions for meeting the new ABET program-specific criteria in optical engineering
}

\author{
Paul O. Leisher*, Sergio C. Granieri, Robert M. Bunch, Azad Siahmakoun, Charles Joenathan \\ Rose-Hulman Institute of Technology, 5500 Wabash Ave., Terre Haute, IN, USA 47803
}

\begin{abstract}
The Accreditation Board for Engineering and Technology (ABET) recently revised their published list of programspecific criteria. Beginning during the 2014-15 cycle, all engineering programs which include "optical" and "photonic" in their titles must meet new specific criteria to receive ABET accreditation. One portion of the wording under the curriculum section states "The curriculum must prepare students to have knowledge of and appropriate laboratory experience in: geometrical optics, physical optics, optical materials, and optical and/or photonic devices and systems." Last year, the Rose-Hulman optical engineering curriculum committee revised our baccalaureate degree program. A portion of this effort sought to improve alignment to the ABET program-specific criteria. Here we review the outcomes of this effort, including our documented continuous improvement process, the realignment of our existing courses along the four tracks laid out by ABET, and the introduction of new undergraduate courses to improve student learning.
\end{abstract}

Keywords: Optical engineering, curriculum development, ABET

\section{INTRODUCTION}

Rose-Hulman Institute of Technology (RHIT) is a private university specializing in teaching engineering, mathematics, and science. Our mission is to provide our students with the world's best undergraduate education in engineering, mathematics and science in an environment of individual attention and support. We offer both a B.S. Optical Engineering (OE) degree and an M.S. OE degree. The optical engineering degree programs at Rose-Hulman formally began in 2003 although we had offered degrees in applied optics at both the bachelors and masters level since 1985 [1,2]. With the name change to optical engineering we sought accreditation by ABET and developed the curriculum from the ground up based on the general ABET criteria [3]. In addition to the General Criteria, the Engineering Accreditation Commission (EAC) of ABET recently adopted additional specific Program Criteria that must be met by all Optical, Photonic, and Similarly Named Engineering Programs [2-4]. As part of our continuous improvement process, and in order to adapt to the new program criteria, the OE curriculum committee has recently made significant changes to the B.S. OE program at Rose-Hulman. This methodology and results of this effort are presented here.

\section{ABET GENERAL CRITERIA AND CONTINUOUS IMPROVEMENT}

Programs seeking accreditation by the ABET Engineering Accreditation Commission (EAC) must satisfy a set of general criteria for baccalaureate-level programs. These general criteria include requirements related to eight areas: 1) Students, 2) Program Educational Objectives, 3) Student Outcomes, 4) Continuous Improvement, 5) Curriculum, 6) Faculty, 7) Facilities, and 8) Institutional Support [3]. Based on Criterion 4, accredited programs must have a documented process which is systematically utilized to drive continuous improvement of the program. Though not explicitly stated, our interpretation of the ABET criteria suggests a top-down, closed-loop approach to continuous improvement. To help describe this approach, four relevant terms must be clearly defined. These terms are listed below and taken directly from [3].

*pleisher@ieee.org

Education and Training in Optics and Photonics: ETOP 2015, edited by Eric Cormier, Laurent Sarger Proc. of SPIE Vol. 9793, 979321 - (C) 2015 SPIE, IEEE, OSA, ICO · doi: 10.1117/12.2223192 
1. Student outcomes (student learning outcomes, or SLO's) “describe what students are expected to know and be able to do by the time of graduation. These relate to the skills, knowledge, and behaviors that students acquire as they progress through the program."

2. Assessment is one or more processes that identify, collect, and prepare data to evaluate the attainment of student outcomes. Effective assessment uses relevant direct, indirect, quantitative and qualitative measures as appropriate to the outcome being measured. Appropriate sampling methods may be used as part of an assessment process.

3. Evaluation is one or more processes for interpreting the data and evidence accumulated through assessment processes. Evaluation determines the extent to which student outcomes are being attained. Evaluation results in decisions and actions regarding program improvement.

Continuous improvement is captured in ABET criteria 2, 3, and 4. The relevant phrasing of these criteria, taken directly from [2], are listed below.

Criterion 2: Program Educational Objectives - "The program must have published program educational objectives that are consistent with the mission of the institution, the needs of the program's various constituencies, and these criteria. There must be a documented, systematically utilized, and effective process, involving program constituencies, for the periodic review of these program educational objectives that ensures they remain consistent with the institutional mission, the program's constituents' needs, and these criteria."

Criterion 3: Student Outcomes - "The program must have documented student outcomes that prepare graduates to attain the program educational objectives. Student outcomes are outcomes (a) through (k) plus any additional outcomes that may be articulated by the program. ..."

Criterion 4: Continuous Improvement - The program must regularly use appropriate, documented processes for assessing and evaluating the extent to which the student outcomes are being attained. The results of these evaluations must be systematically utilized as input for the continuous improvement of the program. Other available information may also be used to assist in the continuous improvement of the program."

Our program's continuous improvement process functions as follows. Program stakeholders (constituents) are regularly identified and polled in order to capture their needs. These needs, along with ABET's requirements and the institute's mission, are used to evaluate and revise (if necessary) the PEOs. The PEOs subsequently drive necessary revisions to the SLOs and the program curriculum. Appropriate performance criteria are established and a systematic assessment process is established to evaluate how well the curriculum does in meeting the SLOs. The assessment results, along with feedback from program stakeholders (e.g. industrial and alumni surveys), are evaluated by the Optical Engineering Curriculum Committee, and necessary modifications to the program are drafted with the goal of improving student attainment of SLOs. The draft program modifications are presented to the Rose-Hulman Institute Curriculum Committee, and pending approval, presented to the entire Institute faculty who have the ultimate authority to approve or reject (based on a majority vote) the curriculum changes. As students graduate and enter the field, their feedback adds to the body of constituents who serve to provide input to ongoing process PEO and SLO review and revision; thus the process in its entirety is closed-loop, as shown in Figure 1. 


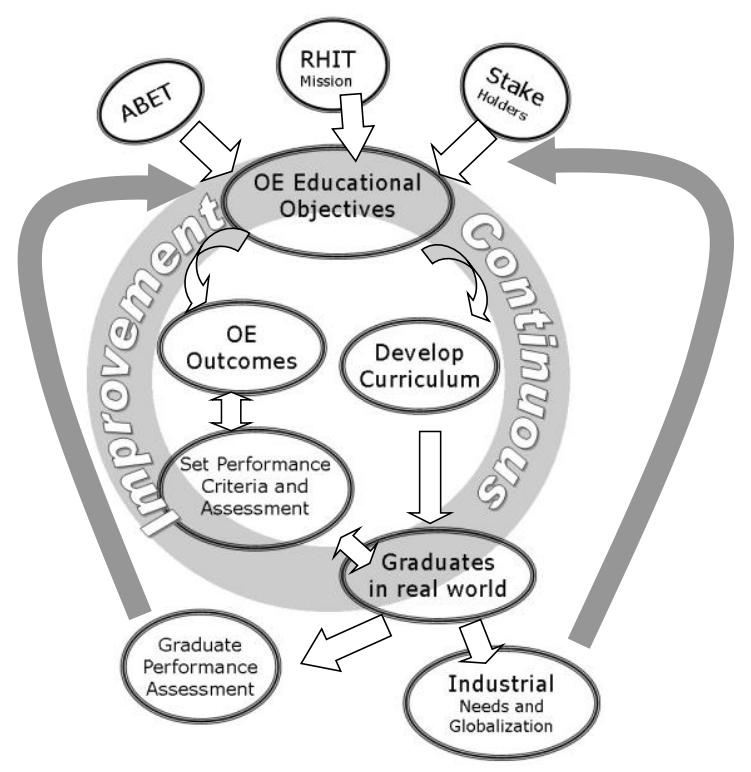

Figure 2. Closed-loop model of the Rose-Hulman Optical Engineering curriculum continuous improvement process.

\section{ABET PROGRAM-SPECIFIC CRITERIA}

In addition to the eight general criteria, each program must also satisfy applicable program-specific criteria (if these exist). The EAC states that "Program Criteria provide the specificity needed for interpretation of the baccalaureate level criteria as applicable to a given discipline" [3]. These program-specific criteria are set by the lead professional society of the area; in the case of optical and photonics engineering, the co-lead societies are SPIE and IEEE. Requirements stated in the program criteria are limited to the areas of curricular topics and faculty.

SPIE was instated as member society of ABET in 2010 (prior to this timeframe, optics and photonic engineering programs had achieved accreditation under the ABET general engineering criteria). In January of 2011, a group led by Barry Shoop and including representatives from industry, academia, and SPIE, began the process of proposing ABET program-specific criteria for optical and photonic engineering [4]. Following a series of reviews and approvals, the EAC adopted the "Program Criteria for Optical, Photonics, and Similarly Named Programs" for programs, including RHIT, seeking accreditation under the 2014-15 published criteria [3].

The program criteria for optical and photonics engineering are presented in Figure 3 [3]. With respect to curriculum, there are several items of note. First, the title of the program appears to matter to a great degree. The program title implies a range of topics, and these topics must covered with appropriate breadth and depth. It is worth noting that the appropriateness is assessed not only internally, but also by the ABET team performing the program general review. In the second part of the program criterion for curriculum, four key areas are clearly distinguished geometrical optics, physical optics, optical materials, and optical and/or photonic devices and systems. Programs must provide both theoretical foundation and hands-on laboratory experience for all of these areas. Our interpretation is that all four of these areas must be covered by optical and photonics engineering programs, but the appropriateness of depth of coverage will depend on each programs' constituencies. Finally, the program criteria for curriculum must prepare students to not just analyze, but also model, design, and realize optical and/or photonic devices and systems. With respect to faculty, the program criteria states that faculty members who teach courses with significant design content must be qualified to do so by virtue of their design experience and subject matter knowledge. This important qualification was clearly put into place in order to safeguard student learning as it pertains to engineering design. Our interpretation of this is part of the program criteria is that when it comes to recruiting and assigning faculty to design courses, subject matter expertise alone is insufficient. The faculty assigned to such courses must also have actual engineering design experience. 


\section{PROGRAM CRITERIA FOR \\ OPTICAL, PHOTONIC, \\ AND SIMILARLY NAMED ENGINEERING PROGRAMS}

Co-Lead Societies: SPIE, the International Society for Optical Engineering or Institute of Electrical and Electronic Engineers

These program criteria apply to all engineering programs that include "optical," "photonic," or similar modifiers in their titles.

\section{Curriculum}

The structure of the curriculum must provide both breadth and depth across the range of engineering topics implied by the title of the program. The curriculum must prepare students to have knowledge of and appropriate laboratory experience in: geometrical optics, physical optics, optical materials, and optical and/or photonic devices and systems.

The curriculum must prepare students to apply principles of engineering, basic sciences, mathematics (such as multivariable calculus, differential equations, linear algebra, complex variables, and probability and statistics) to modeling, analyzing, designing, and realizing optical and/or photonic devices and systems.

\section{Faculty}

Faculty members who teach courses with significant design content must be qualified by virtue of design experience as well as subject matter knowledge.

Figure 3: ABET EAC program-specific criteria for optical, photonic, and similarly named engineering programs.

\section{ADDRESSING THE GENERAL AND PROGRAM-SPECIFIC CRITERIA}

In the Fall of the 2013-2014 academic year, the RHIT OE curriculum committee began work on revising our curriculum to meet the newly published program criteria for optical engineering (at the time, the program criteria were available in draft form). This effort fit into our documented continuous improvement program previously described in section 2 of this manuscript. The overall goal of the effort was to perform a complete review of the curriculum, taking into account the changes proposed by ABET as well as the assessment data collected during the previous cycle and input from our program stakeholders. The steps taken by the committee are listed below:

1. Evaluate previous assessment data as part of the annual continuous improvement process. Review curriculum of other institutes' optical engineering programs (including University of Arizona, Norfolk State University, University of Alabama in Huntsville, University of Central Florida, and University of Rochester). Analyze the existing OE curriculum to identify potential gaps and opportunities.

2. Review list of stakeholders and identify constraints which must be satisfied as part of the curriculum revision process.

3. Utilizing input from program constituents, review and modify (as needed) the program educational objectives (PEOs).

4. Based on the established PEOs, and taking into account prior assessment results, the new ABET program criteria, and the input from program constituents, review and modify (as needed) the student learning outcomes (SLOs).

5. Map the current curriculum to the revised SLOs. 
6. Review course content from all general education (non-OE) courses which are part of the curriculum or could be introduced into the curriculum. Ensure that the SLOs and ABET general and program criteria are being satisfied. Revise program general education requirements as necessary, subject to the constraints identified in step 2 .

7. Perform an in-depth review of every OE course for content (including laboratory work, assignments, and exams). For each course, determine whether or not the course is required with respect to supporting the SLOs. Develop a list of topics and map each course to ensure all topics are covered to sufficient depth. Eliminate required courses which do not appear to support the SLOs, modify existing courses to ensure full coverage of topics, propose new courses where needed to cover gaps identified in step 1, and re-align curriculum to ensure the new ABET program criteria are being satisfied.

8. Present draft version of revised PEOs, SLOs, and curriculum to department for feedback. Revise as needed to satisfy department needs (repeating prior steps as needed), and obtain preliminary department approval. Present revised draft to the other program stakeholders including the affected institute faculty, program industrial advisory board (alumni and employers), the institute graduate school, and students. Incorporate stakeholder feedback and if necessary, re-submit to department. Once approved at the department level, submit curriculum revisions to the institute curriculum committee first, and then the entire instate faculty body for final approval.

9. Develop, document, and execute implementation plan. Publish revised SLOs, PEOs, graduation requirements, and course descriptions. Revise assessment tools, including assessment data collection requirements and student, alumni, and industrial surveys.

Steps 1 through 3 were completed as follows. The OE curriculum committee discovered potential gaps in the areas of linear system theory and non-imaging optical design (lighting and illumination). An opportunity to integrate several topics into a major laboratory experience for students in the junior year was also uncovered. The stakeholder list was reviewed; these stakeholders include students, program faculty, institute faculty, graduate programs, employers, program industrial advisory board, and alumni. A number of constraints which needed to be satisfied by the curriculum revision process were identified; these constraints include following our documented continuous improvement process, maintaining a suitable number of electives in the program, fitting within existing physical space and not adversely affecting the faculty teaching load, meeting institute graduation requirements, and satisfying the new ABET program criteria.

In step 4, the committee reviewed the program educational objectives. As a result of this review process, and supported by the positive input provided by program stakeholders, the decision was made to not modify the PEOs. The RHIT optical engineering program educational objectives are broad statements that describe what graduates are expected to attain within a few years of graduation and are shown in Figure 4.

\section{OE Program Educational Objectives}

- Our graduates will set their career path and advance beyond their entry-level position or progress toward the completion of an advanced degree.

- Our graduates will make a meaningful impact on society.

- Our graduates will behave ethically and act as responsible members of the engineering and science community.

- Our graduates will continue to develop professionally.

Figure 4. RHIT Optical Engineering program educational objectives (PEOs) [5].

Because the program PEOs were left unchanged, the existing SLOs were appropriate for supporting them. However, the OE program had previously adopted our own convention for describing the SLOs. This approach, while valid, had the potential to create some confusion, as they had to be mapped to ABET's student outcome format (ABET ' $a$ ' through ' $k$ ' format [3]). To avoid potential confusion in the future, the OE curriculum committee 
decided to rewrite the program SLOs in order to conform to ABET's general criteria. Figure 5 depicts the revised OE SLOs and describe what students are expected to know and be able to do by the time of graduation. Each major topic has a series of clarifying sub-topics which are not included here (but can be found in the Rose-Hulman course catalog under the optical engineering program of study listing [5]).

\section{OE Student Learning Outcomes}

a) An ability to apply knowledge of mathematics, science, and engineering

b) An ability to design and conduct experiments, as well as to analyze and interpret data

c) An ability to design a system, component, or process to meet desired needs within realistic constraints such as economic, environmental, social, political, ethical, health and safety, manufacturability, and sustainability

d) An ability to function on multidisciplinary teams

e) An ability to identify, formulate, and solve engineering problems

f) An understanding of professional and ethical responsibility

g) An ability to communicate effectively

h) The broad education necessary to understand the impact of engineering solutions in a global, economic, environmental, and societal context

i) A recognition of the need for, and an ability to engage in life-long learning

j) A knowledge of contemporary issues

k) An ability to use the techniques, skills, and modern engineering tools necessary for engineering practice

Figure 5. RHIT Optical Engineering student learning outcomes (SLOs). Note that the additional supporting language which clarifies each objective is not included here, but can be found in [5].

Steps 5 through 7 represent the bulk of the curriculum revision process. The existing program curriculum was mapped to the new SLOs, and work began to close the gaps and leverage the opportunities identified in step 1, subject to the constraints identified in step 2. The program course offerings were aligned to the four tracks (geometrical optics, physical optics, optical materials, and optical/photonic devices and systems). Almost every course description was modified to some degree.

Lab portions from several courses were consolidated into a new large junior-level laboratory course with an emphasis in optomechanics. This course is designed to provide students with additional hands-on exposure to the design, layout, and assembly of benchtop optical experiments and also to foster synthesis with the concepts from the sophomore curriculum in geometrical optics, physical optics, and photonic systems. A new course in linear optical systems was introduced to address the identified gap in linear system theory. Also, a new elective non-imaging optics (lighting and illumination) course was introduced to help the many graduating seniors we have who are entering this rapidly-expanding field.

One course, electro-optics, was removed from the undergraduate curriculum (this course covered mainly advanced topics that were deemed unnecessary for our undergraduate students, and the remaining material was moved other courses). Our lens design course was renamed "Optical System Design" and expanded to include design of other instrumentation (such as spectrometers, couplers, beam expanders, etc.) with a stronger focus on tolerancing and design for manufacturability. Introductory coverage of monochromatic and chromatic aberration theory was added to the sophomore-level paraxial optics course (which was renamed "Geometrical Optics"). The existing optical system course was modified to focus on photonic systems. Major revisions to the capstone senior design sequence were not required; further information on the capstone design course can be found in [2]. Figure 6 summarizes the revised course offerings as aligned to the four tracks from the program criteria. Figure 7 depicts the course descriptions from the newly added courses, a full listing of all course descriptions can be found in [5]. 


\begin{tabular}{|c|c|c|c|c|c|}
\hline \multicolumn{3}{|c|}{ Physical Optics Track } & \multicolumn{3}{|c|}{ Introductory } \\
\hline PH292 & Physical Optics & Required & OE171 & Photography \& Holography & Elective \\
\hline OE392 & Linear Optical Systems & Required & OE172 & Optics in Technology & Required \\
\hline \multirow[t]{2}{*}{ OE495 } & Metrology & Required & & & \\
\hline & & & \multicolumn{3}{|c|}{ Laboratory } \\
\hline \multicolumn{3}{|c|}{ Geometric Optics Track } & OE395 & Optomechanics \& Optical Eng. Lab & Required \\
\hline OE280 & Geometrical Optics & Required & OE415 & Optical Engineering Design I & Required \\
\hline OE480 & Optical System Design & Required & OE416 & Optical Engineering Design II & Required \\
\hline OE434 & Non-Imaging Optics & Elective & OE417 & Optical Engineering Design III & Required \\
\hline \multirow[t]{2}{*}{ OE437 } & Introduction to Image Processing & Elective & & & \\
\hline & & & \multicolumn{3}{|c|}{ Other/Special } \\
\hline \multicolumn{3}{|c|}{ Photonic Systems Track } & OE290 & Directed Research & Elective \\
\hline OE295 & Photonic Devices and Systems & Required & OE490 & Directed Research & Elective \\
\hline OE393 & Fiber Optics and Applications & Required & OE470 & Special Topics & Elective \\
\hline OE450 & Laser Systems and Applications & Required & OE570 & Special Topics & Elective \\
\hline \multirow[t]{2}{*}{ OE493 } & Optical Communications & Elective & & & \\
\hline & & & \multicolumn{3}{|c|}{ Graduate Only } \\
\hline \multicolumn{3}{|c|}{ Materials Track } & OE520 & Principles of Optics & Grad \\
\hline OE360 & Optical Materials & Required & OE485 & Electro-optics & Required \\
\hline \multirow[t]{3}{*}{ OE435 } & Biomedical Optics & Elective & OE592 & Fourier Optics & Grad \\
\hline & & & OE594 & Guided Wave Optics & Grad \\
\hline & & & OE599 & Thesis Research & Grad \\
\hline
\end{tabular}

Figure 6. Required and elective coursework aligned to the four tracks in the program criteria.

OE 392 Linear Optical Systems - Propagation of light and scalar diffraction theory. Fraunhofer and Fresnel diffraction, coherence, Fourier series and transforms, convolution and correlation. Linear system theory, impulse and step response, transfer functions. Coherent and incoherent image formation, optical transfer function (OTF), modulation transfer function (MTF). Image quality assessment methods. Optical information processing applications.

OE 395 Optomechanics \& Optical Engineering Lab - Design, assembly, and alignment of bench top optical systems. Introduction to experimental techniques in optics. Data collection and analysis. Relevant lecture topics including principles of opto-mechanical design, fold mirrors and prisms, lens and mirror mounting, kinematic mounts, precision adjustments and control.

OE 434 Non-Imaging Optics - Lighting, illumination, and solar concentration systems. Radiometry and photometry for illumination, etendue, and concentration. Color coordinates, color vision, and color measurements. Sources, light transfer components, and systems evaluation. Introduction to design methods (edge-ray, compound parabolic concentrator, tailored reflector). Design examples and case studies.

Figure 7. Descriptions for the newly added OE courses. A complete listing can be found in [5].

Figure 8 depicts the revised OE program curriculum flowchart with key prerequisite chains identified. Rose-Hulman operates on an academic quarter system (three quarters per academic year). Courses in the flowchart are designated by the program code, course number, brief title, and credit hours. Six electives are allotted in the program (three general electives, two engineering electives, and one departmental elective). The program codes are as follows: OE - Optical Engineering, PH - Physics, MA - Mathematics, ECE - Electrical and Computer Engineering, ME Mechanical Engineering, EM - Engineering Mechanics, CHEM - Chemistry, CLSK - College and Life Skills, and SV/RH/HSS - Humanities and Social Sciences. A total of 194 credits are required for B.S. Optical Engineering degree. 


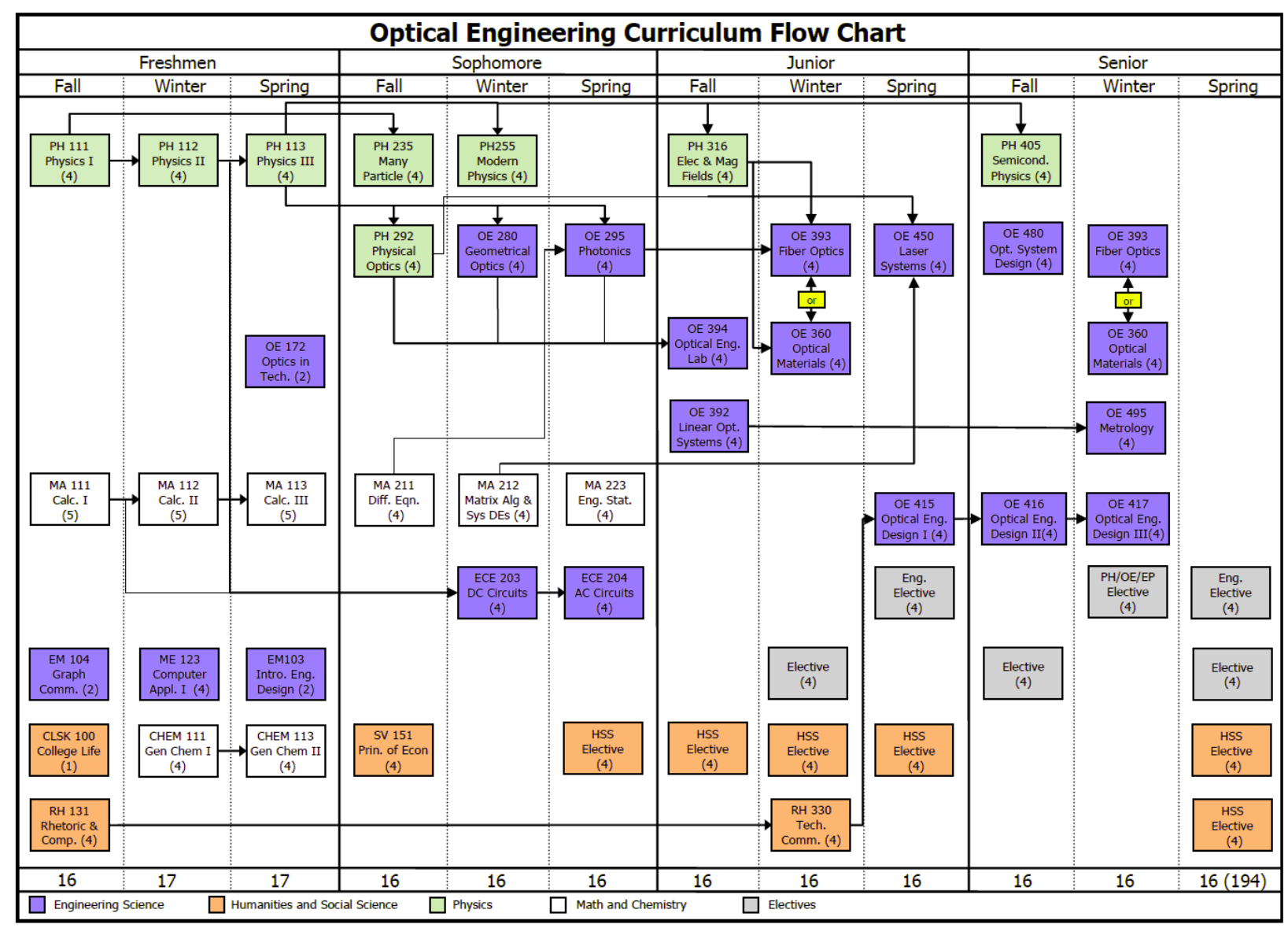

Figure 8. The revised OE program curriculum flow-chart.

\section{SUMMARY}

The Optical Engineering program at Rose-Hulman Institute of Technology was recently revised as part of our documented, closed-loop continuous improvement process and to address the newly released ABET programspecific criteria for optical and Photonics Engineering (and similarly named) programs. The program curriculum was aligned to the four tracks (geometrical optics, physical optics, optical materials, and optical/photonics devices and systems) established in the program criteria. Many courses were modified for content, one was eliminated, and three new courses (two required and one elective) were established.

\section{REFERENCES}

[1] R. M. Bunch, C. Joenathan, and A. Z. Siahmakoun, "From optics to optical engineering: 20 years of optics education at Rose-Hulman Institute of Technology," presented at the Education and Training in Optics and Photonics, 2003.

[2] R. M. Bunch, P. O. Leisher, and S. C. Granieri, "Optical engineering capstone design projects with industry sponsors," Proc. of SPIE, vol. 9188, 2014.

[3] ABET Criteria for Accrediting Engineering Programs. Available: http://www.abet.org/wpcontent/uploads/2015/04/E001-14-15-EAC-Criteria.pdf

[4] B. L. Shoop and K. B. Robinson, "ABET accreditation and optics and photonics engineering: an association whose time has come," Proc. of SPIE, vol. 8481, 2012.

[5] Rose-Hulman Course Catalog - Optical Engineering Program of Study. Available: http://www.rosehulman.edu/course-catalog/course-catalog-2014-2015/programs-of-study/optical-engineering.aspx 